\title{
Aplikasi Edukasi Berbasis Video Untuk Meningkatkan Dukungan Keluarga Mencegah Komplikasi Kaki Diabetes
}

\author{
Ni Komang Teri Wicahyani ${ }^{1}$, Ni Kadek Diah Purnamayanti ${ }^{2 *}$, Putu Agus Windu Yasa \\ Bukian $^{3}$
}

Program Studi Ilmu Keperawatan, Sekolah Tinggi Ilmu Kesehatan Buleleng, Indonesia Jln. Raya Air SaninKm. 11 Bungkulan Singaraja-Bali Tlp.(0362) 3435033

*Email: nikadek2019.stikes@gmail.com

Tanggal submisi: 1 Agustus 2020; Tanggal Penerimaan: 27 Februari 2021

\begin{abstract}
ABSTRAK
Diabetes merupakan penyakit kronis yang sering berujung pada komplikasi vaskular. Komplikasi mikrovaskular pada area distal paling sering terjadi ditandai dengan diabetic foot. Adapun insidensi dan morbiditas komplikasi kaki diabetes dapat cegah dengan deteksi dini. Upaya pemeriksaan kaki yang efektif perlu dilakukan oleh pasien secara mandiri disertai dukungan keluarga. Penelitian ini bertujuan untuk meningkatkan dukungan keluarga untuk membantu pasien diabetes melakukan pencegahan komplikasi kaki. Desain penelitian ini adalah kuasi eksperimen, single group pre-post test design. Intervensi yang diberikan berupa edukasi dengan pendekatan video. Video diadaptasi dari pop up book diabetic foot screening meliputi 12 langkah pemeriksaan tanda dan gejala komplikasi kaki, interpretasi total skor, rekomendasi tindak lanjut, dan perawatan kaki mandiri. Total sample terdiri dari 40 pasang pasien DM dan anggota keluarga yang bersedia menjadi responden penelitian. Berdasarkan hasil uji analisis statistik wilcoxon test, nilai $\mathrm{p}=0.009(\mathrm{p}<0,05)$ dengan median total skor dukungan keluarga sebelum intervensi 77 dan setelah intervensi 81,6. Penelitian ini menyimpulkan edukasi berbasis video dengan konten pemeriksaan kaki untuk mencegah komplikasi kaki diabetes efektif untuk meningkatkan dukungan keluarga.
\end{abstract}

Kata Kunci: Diabetes Melitus, Perawatan Kaki, Dukungan Keluarga, Pemeriksaan Kaki Diabetes

\begin{abstract}
Diabetes is a chronic disease that often results in vascular complications. Microvascular complications in the distal area most often occur marked by diabetic foot. The incidence and morbidity of diabetic foot complications can be prevented by early detection. Effective foot examination needs to be done by the patient independently with family support. This study aims to increase family support to help diabetic patients prevent foot complications. The study design was a quasi-experimental, single group pre-post test design. The intervention given was in the form of education with a video approach. The video adapted from the diabetic foot screening pop up book includes 12 steps examining the signs and symptoms of foot complications, interpretation of the total score, follow-up recommendations, and independent foot care. The total sample consisted of 40 pairs of DM patients and family members who were willing to become research respondents. Based on the results of the Wilcoxon test statistical analysis, the value of $p=0.009$ ( $p<0.05)$ with the median total score of family support before intervention 77 and after intervention 81.6. This research concludes video-based education with foot examination content to prevent diabetes foot complications effectively to increase family support.
\end{abstract}


ISSN 1979-7621 (Print). ISSN 2620-7761 (Online).

DOI : $10.23917 /$ jk.v14i1.11749

\section{PENDAHULUAN}

Diabetes Melitus (DM) merupakan suatu penyakit metabolik dengan karakteristik hiperglikemia yang terjadi karena kelainan sekresi insulin, kerja insulin, maupun keduanya. Penyakit DM secara garis besar terjadi disebabkan adanya disfungsi Sel Beta pada Pangkreas yang menyebabkan terjadinya retensi insulin sehingga terjadi hiperglikemia

World Health Organization (WHO) pada tahun 2015 memperkirakan jumlah penduduk dunia yang menderita DM pada tahun 2030 meningkat paling sedikit menjadi 366 juta. Total jumlah penderita DM pada tahun 2015 tercatat 415 juta orang dan diperkirakan pada tahun 2040 jumlah penderita DM akan menjadi 642 juta orang. Data regional International Diabetes Federation (IDF) Atlas tahun 2017 melaporkan bahwa epidemi Diabetes di Indonesia masih menunjukkan kecenderungan meningkat. Indonesia adalah negara peringkat keenam di dunia setelah Tiongkok, India, Amerika Serikat, Brazil dan Meksiko dengan jumlah penyandang Diabetes usia 20-79 tahun sekitar 10,3 juta orang (Kementerian Kesehatan Republik Indonesia, 2018).

Komplikasi diabetes militus salah satunya yaitu kompikasi kaki diabetes karena kurangnya informasi dan pemahaman dari pasien diabetes dalam mengenali tanda dan gejala yang dapat menyebabkan masalahkaki diabetes sehingga terjadi keterlambatan penanganan atau perawatan. Hal ini dapat dicegah melalui perawatan kaki (Permadani, 2017).

Dukungan keluarga dapat memberikan dampak yang signifikan terhadap perilaku perawatan kaki pada DM. Keluarga dapat membantu secara mental dan fisik, bantuan mental yang berikan keluarga yaitu berbentuk dukungan moral dan motivasi pada penderita DM dalam melakukan perawatan kaki. Bantuan fisik yang keluarga berikan seperti menyediakan alat bantu dalam perawatan kaki (Novita Setyowati, 2019). Untuk meningkatkan keefektifan pemahaman keluarga pasien dalam mendeteksi tanda masalah kaki diabetes digunakan suatu media edukasi yaitu pop up book diabetic foot screening yaitu suatu media buku 2 dimensibuku yang bisa berpotensi gerak dan interaksi melalui penggunaan mekanisme kertas seperti lipatan, slide, gulungan, dan roda yang menjelaskan tentang mendekteksi tanda masalah kaki pada pasien diabetes melitus sehingga keluarga dan pasien dapat secara efektif melakukan penanganan dan perawatan. Penggunaan media pop up book memiliki kelebihan antara lain memberikan sebuah cerita yang menarik dimulai dari adanya tampilan yang berdimensi yaitu pada gambar dan ketika halaman buku dibuka bagian tertentu nantinya bisa bergeser, memberikan sebuah kejutan yang dapat mengundang ketakjuban ketika halaman buku pop up dibuka yang nantinya pembaca akan menanti kejutan pada halaman berikutnya, kesan yang disampaikan dalam sebuah cerita semakin kuat, dan tampilan yang mempunyaidimensi membuat cerita seperti nyata dengan ditambahnya kejutan yang ada pada halaman berikutnya (Solichah, 2018). Berdasarkan hasil studi pendahuluan yang dilakukan peneliti tanggal 15 Januari 2020 didapatkan bahwa populasi pasien DM di STIKes Buleleng sejumlah 65 orang. Pasien DM ini merupakan keluarga dari mahasiswa STIkes Buleleng. Pada saat melakukan wawancara dengan media online kepada pasien DM, pasien mengatakantidak bisa melakukan perawatan kaki secara mandiri, dan sebagian besar keluarga tidak bisa membantu karena memiliki kesibukan masing-masing.

\section{METODE PENELITIAN}

Jenis penelitian yang digunakan adalah penelitian quasi-eksperimen 
Ratnasari, I Arifah \& T A I Kusumaningrum / Jurnal Kesehatan 14 (1) 2021, 79-86

dengan pendekatannya onegroup prepost test design. Penelitian ini telah dilaksanakan di Stikes Buleleng pada bulan April 2020 dengan meminta persetujuan responden menggunakan informconsent. Output diukur dengan insturmen dukungan keluarga 25 item dukungan informational, instrumental, penilaian dan penghargaan, dan emosional.

Populasi dalam penelitian ini adalah semua mahasiswa yang memiliki keluarga dengan DM di Sekolah Tinggi Ilmu Kesehatan Buleleng, Bali. Dengan pendekatan purposive sampling hanya melibatkan mahasiswa keperawatan sebagai keluarga pasien DM terdapat 40 pasang responden yang bersedia mengikuti penelitian. Teknis pengambilan data pretest dilakukan dengan media komunikasi Whatsaapp. Peneliti melakukan wawancara data karakteristik dan pretest.Selanjutnya peneliti mengirimkan video edukasi berdurasi 12 menit yang berisi konten pemeriksaan kaki, interpretasi total skor, dan rekomendasi perawatan. Untuk memastikan, keluarga dan pasien telah mengerti dan dapat melakukan pemeriksaan sesuai protokol, responden wajib mengirimkan video balasan berupa rekaman pemeriksaan yang dilakukan secara mandiri. Peneliti melakukan validasi hasil pemeriksaan dan melakukan validasi dan menerima feedback responden terkait prosedur pemeriksaan. Post test dilakukan secara daring 1 minggu setelah pretest dalam bentuk google form yang diisi oleh responden.

\section{HASIL DAN PEMBAHASAN}

\section{Karakteristik Keluarga Responden}

Berdasarkan tabel 1 dapat diketahui 40 keluarga responden, umur 10-umur 16-20 sebanyak 4 (10\%), umur 21-25 tahun sebanyak $36(90 \%)$ dan jumlah responden keluarga pasien berjenis kelamin laki-laki yaitu 5 $(12,5 \%)$ dan Perempuan berjumlah 35 $(87,5 \%)$. Keluarga pasien yang memiliki hubungan ibu dengan pasien berjumlah 29 (72,5\%), hubungan bapak dengan pasien berjumlah $9(22,5 \%)$, hubungan kakek dengan pasien berjumlah $1(2,5 \%)$ dan hubungan nenek dengan pasien berjumlah $1(2,5 \%)$. Keluarga pasien diketahui yang memiliki program studi Keperawatan berjumlah 40 (100\%), Keluarga pasien yang memiliki semester 8 berjumlah 34 (85\%), Semester 6 berjumlah berjumlah $2(5 \%)$, Semester 4 berjumlah $4(10 \%)$,. Keluarga pasien yang sudah mendapat pelajaran tentang Diabetes Melitus berjumlah 35 (87,5\%), dan keluarga pasien yang belum mendapat pelajaran tentang Diabetes Melitus berjumlah 35 (12,5\%).

\section{Tabel 1 Karakteristik Keluarga Responden}

\begin{tabular}{|c|c|c|}
\hline $\begin{array}{l}\text { Karakteristik } \\
\text { Keluarga }\end{array}$ & Frekuensi & Persentase $(\%)$ \\
\hline \multicolumn{3}{|l|}{$\begin{array}{l}\text { Umur Keluarga } \\
\text { (tahun) }\end{array}$} \\
\hline $16-20$ & 4 & 10,0 \\
\hline $21-25$ & 36 & 90,0 \\
\hline \multicolumn{3}{|l|}{$\begin{array}{l}\text { Jenis Kelamin } \\
\text { Keluarga }\end{array}$} \\
\hline Laki-laki & 5 & 12,5 \\
\hline Perempuan & 35 & 87,5 \\
\hline \multicolumn{3}{|l|}{$\begin{array}{l}\text { Hubungan } \\
\text { dengan Pasien }\end{array}$} \\
\hline Ibu & 29 & 72,5 \\
\hline Bapak & 9 & 22,5 \\
\hline Kakek & 1 & 2,5 \\
\hline Nenek & 1 & 2,5 \\
\hline \multicolumn{3}{|l|}{ Program Studi } \\
\hline Tidak Kuliah & 0 & 0 \\
\hline Keperawatan & 40 & 100 \\
\hline \multicolumn{3}{|l|}{ Semester } \\
\hline 4 & 4 & 10 \\
\hline 6 & 2 & 5,0 \\
\hline 8 & 34 & 85 \\
\hline \multicolumn{3}{|l|}{$\begin{array}{l}\text { Mendapat } \\
\text { Pelajaran }\end{array}$} \\
\hline Sudah & 35 & 87,5 \\
\hline Belum & 5 & 12,5 \\
\hline Total & 40 & 100 \\
\hline
\end{tabular}

\section{Karakteristik Responden}

Bedasarkan tabel 2 diketahui dari 40 responden yang memiliki umur 30-35 tahun berjumlah 2 (5\%), umur $41-45$ berjumlah 7 $(17,5 \%)$, umur $46-50$ (19\%), umur 51-56 berjumlah $5(12,5 \%)$, umur 61-65 berjumlah 
Ratnasari, I Arifah \& T A I Kusumaningrum / Jurnal Kesehatan 14 (1) 2021, 79-86

$1(2,5 \%)$, umur 66-70 berjumlah $1(2,5 \%)$, umur 70 keatas berjumlah 1 (2,5\%). responden pasien berjenis kelamin laki-laki yaitu 8 (20\%) dan Perempuan berjumlah 32 (80\%).Responden yang memiliki tingkat pendidikan perguruan tinggi berjumlah 3 (7,5\%), Tingkat Pendidikan SMA 21 (52,5\%), Tingkat Pendidikan SMP 6 $(15,0 \%)$, Tingkat Pendidikan SD 21 $(22,5 \%)$, dan Tidak Tamat SD berjumlah 1 $(2,5 \%)$ Responden yang memiliki pekerjaan Nelayan/Petani berjumlah 5 (12,5\%), pekerjaan Wiraswasta berjumlah $7(17,5 \%)$, pekerjaan Pegawai Swasta berjumlah 3 (7,5\%), pekerjaan Ibu Rumah Tangga/Pensiunan/Tidak Bekerja berjumlah $25(62,5 \%)$. Responden yang memiliki tingkat penghasilan Rp 2.000.0003.000.000 berjumlah 10 (25\%), tingkat penghasilan $\mathrm{Rp}$ 500.000-1.000.000 berjumlah 16 (40\%), dan tingkat penghasilan $<\mathrm{Rp} 500.000$ berjumlah 14 $(35 \%)$. Responden yang lama menderita $\mathrm{DM}<5$ tahun berjumlah $31(77,5 \%)$ dan lama menderita DM 4-10 tahun berjumlah 9 $(22,5 \%)$. Sumber informasi terkait dengan perawatan DM didapatkan oleh responden melalui TV berjumlah $10 \quad(25 \%)$ dan melalui internet sejumlah $30 \quad(75 \%)$. Penyakit penyerta yang diderita oleh responden yaitu Hipertensi berjumlah 35 $(87,5 \%)$, penyakit penyerta Jantung berjumlah $2(5 \%)$, penyakit penyerta Asma berjumlah $1(2,5 \%)$, dan penyakit penyerta Radang Sendi berjumlah 2 (5\%). Responden yang mendapat dukungan keluarga berjumlah 40 (100\%) sedangkan yang tidak mendapat dukungan keluarga berjumlah 0 (0\%). Responden yang mendapat motivasi berjumlah 40 (100\%) sedangkan yang tidak mendapat motivasi berjumlah $0(0 \%)$. Responden yang pernah diedukasi terkait tentang perawatan DM berjumalh 26 (65\%) dan pasien yang tidak pernah diedukasi berjumlah 14 (35\%).Responden diketahui yang pasien yang mengkonsumsi obat berjumlah 34 $(85 \%)$ dan yang tidak mengkonsumsi obat berjumlah $6(15 \%)$.

Tabel 2 Karakteristik Responden

\begin{tabular}{lll}
\hline $\begin{array}{l}\text { Karakteristik } \\
\text { Pasien }\end{array}$ & $\begin{array}{l}\text { Frekuens } \\
\text { i }\end{array}$ & $\begin{array}{l}\text { Persentas } \\
\text { e (\%) }\end{array}$ \\
\hline Umur (tahun) & & \\
$30-35$ & 2 & 5,0 \\
$36-40$ & 0 & 0 \\
$41-45$ & 7 & 17,5 \\
\hline
\end{tabular}

\begin{tabular}{lll}
\hline $46-50$ & 19 & 47,5 \\
$51-55$ & 4 & 10,0 \\
$56-60$ & 5 & 12,5 \\
$61-65$ & 1 & 2,5 \\
$66-70$ & 1 & 2,5 \\
70 ke atas & 1 & 2,5
\end{tabular}

\begin{tabular}{lll}
\hline Jenis Kelamin & & \\
Laki-laki & 8 & 20,0 \\
Perempuan & 32 & 80,0
\end{tabular}

Tingkat Pendidikan

\begin{tabular}{lll}
\hline Tingkat Pendidikan & & \\
Tidak Tamat SD & 1 & 2,5 \\
SD & 9 & 22,5 \\
SMP & 6 & 15,0 \\
SMA & 21 & 52,5 \\
Perguruan Tinggi & 3 & 7,5
\end{tabular}

\begin{tabular}{lll}
\hline $\begin{array}{l}\text { Pekerjaan } \\
\text { Tidak }\end{array}$ & 25 & 62,5 \\
$\begin{array}{l}\text { Bekerja/Pensiunan/Ib } \\
\text { u Rumah Tangga }\end{array}$ & & \\
$\begin{array}{l}\text { Pegawai Swasta } \\
\text { Wiraswasta }\end{array}$ & 3 & 7,5 \\
Petani/Nelayan & 7 & 17,5 \\
& 5 & 12,5 \\
\hline $\begin{array}{l}\text { Pendapatan } \\
\text { <Rp 500.000 }\end{array}$ & 14 & 35,0 \\
Rp 500.000- & 16 & 40,0 \\
1.000 .000 & & \\
Rp 2.000.000- & 10 & 25,0 \\
3.000 .000 & & \\
\end{tabular}

\begin{tabular}{lll}
\hline $\begin{array}{l}\text { Lama Menderita } \\
\text { DM }\end{array}$ & \\
<5 Tahun & 31 & 77,5 \\
5-10 Tahun & 9 & 22,5 \\
& & \\
\hline Sumber Informasi & & \\
TV & 10 & 25,0 \\
Internet & 30 & 75,0 \\
& & \\
\hline
\end{tabular}

\begin{tabular}{lll}
\hline Penyakit Penyerta & & \\
Hipertensi & 35 & 87,5 \\
Jantung & 2 & 5,0 \\
Asma & 1 & 2,5 \\
Radang Sendi & 2 & 5,0
\end{tabular}

\begin{tabular}{lll}
\hline Mendapat Motivasi & & \\
Ya & 40 & 100 \\
Tidak & 0 & 0
\end{tabular}

\begin{tabular}{lll}
\hline Mengkonsumsi & & \\
Obat & & \\
Ya & 34 & 85,0 \\
Tidak & 6 & 15,0 \\
& & \\
\hline
\end{tabular}

\begin{tabular}{lll}
\hline Pernah Diedukasi & & \\
& & \\
Ya & 26 & 65 \\
Tidak & 14 & 35 \\
& & \\
\hline Total & 40 & 100 \\
\hline
\end{tabular}




\section{Tingkat Dukungan Keluarga Sebelum Diberikan Intervensi}

Tabel 3Tingkat Dukungan Keluarga Sebelum Diberikan Intervensi
Pengujian statistik menggunakan program SPSS 25.0 for windows dengan uji statistik Wilxocon Rank Test dengan tingkat signifikansi $(\mathrm{p}=0,05)$. Didapatkan hasil analisa nilai signifikansi uji statistic dengan menggunakan Wilxocon Rank Test yaitu 0,009 yang berarti $\mathrm{p}<0,05$,

\begin{tabular}{ccc}
\hline $\begin{array}{c}\text { Tingkat Dukungan } \\
\text { Keluarga }\end{array}$ & Frekuensi & Prosentase(\%) \\
\hline Buruk & 1 & 2.5 \\
Sedang & 9 & 22.5 \\
Baik & 30 & 75.0 \\
\hline Total & 40 & 100.0
\end{tabular}

Berdasarkan table 3 diketahui dari 40 responden diketahui yang responden dengan tingkat dukungan keluarga buruk berjumlah $1(2,5 \%)$, tingkat dukungan keluarga sedang berjumlah $9(22,5)$, dan jumlah dukungan keluarga baik berjumlah $30(75 \%)$.

\section{Tingkat Dukungan Keluarga Setelah Diberikan Intervensi}

Tabel 4 Tingkat Dukungan Keluarga Setelah Diberikan Intervensi

\begin{tabular}{ccc}
\hline $\begin{array}{c}\text { Tingkat } \\
\text { Dukungan } \\
\text { Keluarga }\end{array}$ & Frekuensi & Prosentase(\%) \\
\hline Buruk & 0 & 0 \\
Sedang & 7 & 17,5 \\
Baik & 33 & 82.5 \\
\hline Total & 40 & 100.0
\end{tabular}

Berdasarkan Tabel 4 diketahui dari 40 responden diketahui yang responden dengan tingkat dukungan keluarga buruk berjumlah $0 \quad(0 \%)$, tingkat dukungan keluarga sedang berjumlah $7(7,5)$, dan jumlah dukungan keluarga baik berjumlah $33(82,5 \%)$.

\section{Pengaruh Edukasi Berbasis Video Terhadap Dukungan Keluarga dalam Perawatan Kaki pada Pasien DM Tipe 2}

Tabel 5 Hasil Analisa Statistik

\begin{tabular}{ccc}
\hline & $\begin{array}{c}\text { Median } \\
\text { (Minimum- } \\
\text { Maksimum) }\end{array}$ & Nilai p \\
\hline $\begin{array}{c}\text { Tingkat Dukungan } \\
\text { Keluarga Sebelum } \\
\text { Edukasi }\end{array}$ & $78(30-100)$ & 0,009 \\
$\begin{array}{c}\text { Tingkat Dukungan } \\
\text { Keluarga Setelah } \\
\text { Edukasi }\end{array}$ & $81,5(50-97)$ & \\
& \\
\hline
\end{tabular}
maka HO ditolak dan Ha diterima, sehingga dapat disimpulkan ada perbedaan dukungan keluarga dalam perawatan kaki pada pasien DM tipe 2 sebelum dan setelah intervensi.

Hasil penelitian ini sesuai dengan penelitian yang dilakukan oleh Munali pada tahun 2019 yang berjudul "Edukasi Kesehatan: Perawatan Kaki Terhadap Pengetahuan, Sikap Dan Tindakan Pencegahan Ulkus Kaki Diabetik", pemberian edukasi kepada pasien DM dapat meningkatkan pemahaman dan meningkatkan tindakan pasien dalam melakukan perawatan kaki untuk mencegah komplikasi (Munali, 2019)

Menurut penelitian yang dilakukan oleh Amilia pada tahun 2018 yang berjudul "Hubungan Pengetahuan, Dukungan Keluarga Serta Perilaku Penderita Diabetes Melitus Tipe 2 Terhadap Kejadian Ulkus Kaki Diabetes", terdapat banyak factor yang mempengarui terjadinya komplikasi pada kaki diabetes melitus salah satunya yaitu dukungan keluarga. Hal ini sejalan dengan penelitian ini, dukungan keluarga dapat memberikan dukungan informatif dalam bentuk informasi tentang perawatan kaki maupun memberikan dukungan emosional seperti memberikan motivasi, ketenangan, menemani saat melakukan perawatan dan dapat juga memberikan dukungan material (Amilia, 2018)

Menurut penelitain wahyuni tahun 2019 yang berjudul "Efektivitas Edukasi Pasien Diabetes Mellitus Tipe 2 Terhadap Pengetahuan dan Kontrol Glikemik Rawat Jalan di RS Anwar Medika", pemberian edukasi atau pengetahuan dapat memberikan pengaruh yang signifikan terhadap penurunan kadar gula darah pada pasien diabetes militus tipe 2 . Disamping itu terdapat perubahan perilaku yang posif pada pasien dalam kepatuhan dalam terapi pengobatan 
Ratnasari, I Arifah \& T A I Kusumaningrum / Jurnal Kesehatan 14 (1) 2021, 79-86

Menurut penelitian yang dilakukan oleh Fatmah Zakaria tahun 2017 yang berjudul "Pengaruh Pendidikan Kesehatan Dengan Media Audiovisual Terhadap Pengetahuan Dan Sikap Ibu Tentang Inisiasi Menyusu Dini Di Kota Yogyakarta", edukasi kesehatan dengan menggunakan media audiovisual atau video dapat merangsang otak untuk menyerap dan menyimpan pesan serta kemampuan dalam mengingat pesan. Kemampuan otak dalam mengingat pesan dengan media audio $10 \%$, visual $40 \%$, audiovisual $50 \%$. Untuk tingkat kemampuan menyimpan pesan berdasarkan media audio $(<3$ hari $70 \%$, $>3$ hari $10 \%)$, media visual $(<3$ hari $72 \%$, > 3 hari 20\%), dan media audiovisual (< 3 hari $85 \%$, > 3 hari $65 \%$ ). Edukasi menggunakan media video yang mengaplikasi pemeriksaan kaki diabetes dapat merubah sikap dan dukungan keluarga dalam melakukan perawatan kaki pada pasien DM, hal ini tercermin dari hasil rata-rata dukungan keluarga sebelum dan sesudah diberikan edukasi dengan nilai rata-rata meningkat dari 77 menjadi 81,6. Hasil data ini didapatkan menggunakan instrument yang digunakan berupa kuesioner. Kuesioner yang digunakan dalam penelitian ini adalah Kuesioner dukungan keluarga dalam pelaksanan perawatan kaki menurut Vriska Anjasari, 2018 yang sudah dimodifikasi (Zakaria, 2017)

Pada saat melakukan penelitian ini terdapat banyak hambatan yang dialami oleh peneliti yaitu adanya hambatan teknologi dan koneksi internet. Peneliti berkomunikasi dengan pasien DM dikarenakan menggunakan media online sehingga ada kendala dalam hal internet maupun teknologi dalam hal durasi pengiriman video yang sangat panjang. Komunikasi dengan menggunakan media online juga membuat susah dalam membaca respon nonverbal pasien apakah pasien sudah benar mengerti saat diberikan edukasi.

Pada penelitian ini juga mendapat respon atau feedback postif dari responden beserta keluarganya. Keluarga dan responden mengatakan sangat terbantu dan menjadi paham tentang pentingnya informasi kesehatan dan pentingnya dukungan keluarga dalam melakukan perawatan kaki pada pasien DM.

\section{KESIMPULAN}

Pada penelitian ini dapat disimpulkan bahwa pemberian edukasi berbasis video cukup efektif meningkatkan dukungan keluarga dalam pencegahan komplikasi kaki diabetes. Distribudi media video perlu memperhatikan faktor teknis berkaitan dengan besaran data, bandwidh dan signal pengguna. Penelitian selanjutnya merekomendasikan penyempurnaan item pemeriksaan dan adaptasi konten serta media edukasi syncronized approach yang memungkinkan adanya interaksi langsung dengan tenaga kesehatan.

\section{UCAPAN TERIMAKASIH}

Peneliti mengucapkan terima kasih pada mahasiswa Sekolah Tinggi Ilmu Kesehatan Buleleng beserta keluarga yang menjadi responden penelitian telah berpartisipasi dalam aktif dalam melaksanakan program edukasi pencegahan komplikasi kaki diabetes. 


\section{DAFTAR PUSTAKA}

Amilia, Y. (2018). Hubungan Pengetahuan, Dukungan Keluarga Serta Perilaku Penderita Diabetes Melitus Tipe 2 Terhadap Kejadian Ulkus Kaki Diabetes. https://ejournal3.undip.ac.id/index.php/jkm/article/download/19891/18805

Anas Rahmad Hidayat, I. N. (2014). Perawatan Kaki Pada Penderita Diabetes Militus Di Rumah. Jurnal Permata Indonesia, 5, 49-54.

Andra Saferi Wijaya, Yessie Mariza Putri. (2013). Keperawatan Medikal Bedah.

Bhatt, H., Saklani, S., \& Upadhayay, K. (2016). Anti-oxidant and anti-diabetic activities of ethanolic extract of Primula Denticulata Flowers. Indonesian Journal of Pharmacy, 27(2), 74-79. https://doi.org/10.14499/indonesianjpharm27iss2pp74

Erdiana, Y. (2016). Dukungan Keluarga Dalam Kunjungan Lansia Di Posyandu Lansia.

Friedman. (2013). Keperawatan Keluarga. Gosyen Publishing.

Iii, B. A. B. (2015). Kerangka Konsep Kerangka konseptual penelitian adalah keterkaitan antara konsep yang satu dengan konsep lainnya dari masalah yang ingin diteliti ( Setiawan \&. 40-43.

International Diabetic Federation. (2017). IDF Clinical Practice Recommendations on the Diabetic Foot.

Katuuk, M. E. (2017). Hubungan Dukungan Sosial Dan Motivasi Dengan Perawatan Mandiri Pada Pasien Diabetes Dalam Rsud Mokopido Toli-Toli. E-Journal Keperawatan, 5(1, Februari).

Mubarokah, A. (2016). Keefektifan Penerapan Media Pembelajaran Buku Pop-Up Terhadap Minat Dan Hasil Belajar Siswa Materi Seni Rupa Murni Kelas Iv Sd Negeri 1 Jombor Kabupaten Temanggung. https://lib.unnes.ac.id/24513/

Munali. (2019). Edukasi Kesehatan: Perawatan Kaki Terhadap Pengetahuan, Sikap Dan Tindakan Pencegahan Ulkus Kaki Diabetik. https://ejournal.unair.ac.id/CMSNJ/article/view/13241/pdf

Novita Setyowati, P. S. (2019). Pengaruh Peran Keluargaterhadap Regulasi Kadar Gula Darah Penderita Dm. Jurnal Perawat Indonesia, 3, 85-92.

Perkeni. (2015). Kriteria Diagnostik DM Tipe 2. In Konsensus Pengelolaan dan Pencegahan Diabetes Melitus Tipe 2 di Indonesia.

Plores, L. (2018). Hubungan Dukungan Keluarga Dengan Perawatan Kaki Pada Pasien Diabetes Melitus di Puskesmas Padang Bulan Medan.

Resty, A. (2012). Faktor-faktor yang melatarbelakangi perilaku perawatan kaki pada pasien diabetes mellitus di RSUD Sumedang. E-Jurnal Mahasiswa, 1(1).

Restyana Noor Fatimah. (2015). Diabetes Melitus Tipe 2. J MAJORITY, 4. 
Rudy bilous, richard donelly. (2015). diabetes ( s. ke. ns. barrarah bariid (ed.); 4th ed.).

Sucipto, K. W., Firdausa, S., Zufry, H., \& Ekdamayanti, A. S. (2019). The 3rd Aceh Endocrinology \& Diabetes Update (AEDU) 2019. The Tailoring Art of Innovative Approaches To Fight Endocrine Disorders, 170-175.

Sugiyono. (2010). Metode Penelitian Pendidikan Pendekatan Kuantitatif, kualitatif, dan R\&D. Alfabeta.

Ulya, Y., Arsyad, A., Syamsuddin, S., \& Ulya, Y. (2018). Nusantara Medical Science Journal. $11-17$.

Windani Mambang Sari, C., Haroen, H., \& Nursiswati, N. (2016). Pengaruh Program Edukasi Perawatan Kaki Berbasis Keluarga terhadap Perilaku Perawatan Kaki pada Pasien Diabetes Melitus Tipe 2. Jurnal Keperawatan Padjadjaran, v4(n3), 305-315. https://doi.org/10.24198/jkp.v4n3.10

Zakaria, F. (2017). Pengaruh Pendidikan Kesehatan Dengan Media Audiovisual Terhadap Pengetahuan Dan Sikap Ibu Tentang Inisiasi Menyusu Dini Di Kota Yogyakarta. http://digilib.unisayogya.ac.id/2397/1/NASKAH PUBLIKASI THESIS FATMAH ZAKARIA.pdf 
Ratnasari, I Arifah \& T A I Kusumaningrum / Jurnal Kesehatan 14 (1) 2021, 79-86 